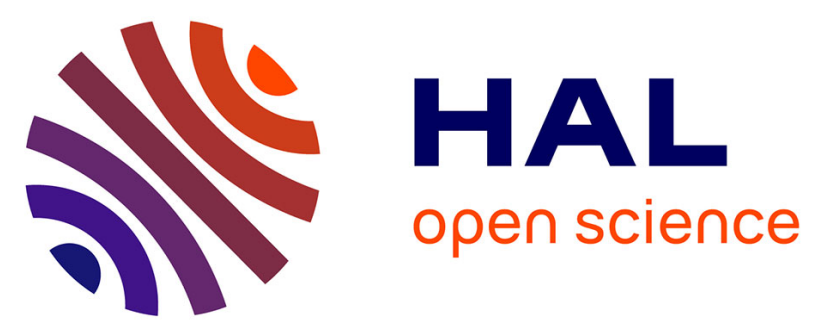

\title{
A Switch in the Hydrophobic/Hydrophilic Gas-Adsorption Character of Prussian Blue Analogues: An Affinity Control for Smart Gas Sorption
}

Lotfi Boudjema, Jérôme Long, Fabrice Salles, Joulia Larionova, Yannick Guari, Philippe Trens

\section{To cite this version:}

Lotfi Boudjema, Jérôme Long, Fabrice Salles, Joulia Larionova, Yannick Guari, et al.. A Switch in the Hydrophobic/Hydrophilic Gas-Adsorption Character of Prussian Blue Analogues: An Affinity Control for Smart Gas Sorption. Chemistry - A European Journal, 2018, 25, pp.479-484. 10.1002/chem.201804730 . hal-02001852

\section{HAL Id: hal-02001852 https://hal.science/hal-02001852}

Submitted on 14 Jan 2021

HAL is a multi-disciplinary open access archive for the deposit and dissemination of scientific research documents, whether they are published or not. The documents may come from teaching and research institutions in France or abroad, or from public or private research centers.
L'archive ouverte pluridisciplinaire HAL, est destinée au dépôt et à la diffusion de documents scientifiques de niveau recherche, publiés ou non, émanant des établissements d'enseignement et de recherche français ou étrangers, des laboratoires publics ou privés. 


\title{
Switch in the hydrophobic-hydrophilic gas-adsorption character of the Prussian Blue Analogues: an affinity control for smart gas sorption.
}

\author{
Lotfi Boudjema $^{[a]}$, Jérôme Long ${ }^{[b]}$, Fabrice Salles ${ }^{[c]}$, Joulia Larionova ${ }^{[b]}$, Yannick Guari[b] and Philippe \\ Trens*[a]
}

\begin{abstract}
Porous coordination polymers are molecule-based materials presenting a high degree of tunability, which offer many advantages for targeted applications over conventional inorganic materials. We demonstrate here that the hydrophilic-hydrophobic character of Prussian blue analogues having a lipophilic feature may be tuned to optimize the gas adsorption properties. The role of the coordinatively unsaturated metal sites is emphasized through a combination of theoretical and experimental study of water, ethanol and $n$-hexane adsorption.
\end{abstract}

Porous coordination polymers are exciting molecule-based materials, made of metal ion nodes and molecular building blocks, which have attracted a great deal of attention for several decades not only from the fundamental point of view, but also due to potential technological applications in several fields including catalysis, gas storage, separation and purification. The most explored families of porous coordination polymers belong to Metal Organic Frameworks (MOFs) ${ }^{[1,2]}$ and Prussian Blue Analogues (PBA) ${ }^{[3]}$ have been investigated as promising alternatives for activated carbon or zeolite materials usually used in industry for gas storage $\mathrm{e}^{[4]}$ or separation/purification processes. ${ }^{[5-7]}$ They present many advantages in comparison with conventional inorganic porous adsorbers consisting in: (i) "soft" chemistry routes for their synthesis, (ii) thermal and hydrothermal stability, (iii) comparable or higher adsorption capacities, (iv) structural flexibility providing the possibility to easily adjust the pore size and topology, ( $v$ ) adjustable chemical composition permitting to optimize the physico-chemical properties of adsorption sites, such as the Coordination Unsaturated Sites (CUS), (vi) functionalization ability offering the possibility to tune the affinity between the host network and the guest molecules..$^{[3,8]}$ In particular, the adjustability of the hydrophobic/hydrophilic character of these materials, independently to their lipophilic/lipophobic balance, to finely adapt the interaction between guest molecules and host frameworks by using different approaches appears as a fundamental point for optimizing the adsorption properties. ${ }^{[9,10]}$ In the targeted applications where adsorption is the main process, the surface chemistry of materials is indeed of prime importance. ${ }^{[11]}$ In the case of MOFs, several strategies have been undertaken in order to adapt the affinity of the host network either for favouring or disfavouring interactions with sorbates: $(I)$ the post-synthetic ${ }^{[12-14]}$ or in-situ ${ }^{[15-17]}$ functionalization of the framework, (ii) the modification of the CUS nature or their saturation to prevent strong interactions between metal center and sorbate molecules, ${ }^{[18]}$ or (iii) the introduction of extra-framework charges by using for instance hydrophilic alkali or hydrophobic organic cations. ${ }^{[19],}{ }^{[20]}$ In all these cases, the hydrophobic/hydrophilic character of the network is governed by the nature of the organic functionalities, metal ions, CUS, which modify the hydrophilic-hydrophobic balance by varying the nature of the interactions (strong covalent interactions, electrostatic or van der Waals interactions, $\mathrm{H}$-bond interactions and hydrophobic interactions) of the solid network with guest species. Thus, in general cases, such modification of the hydrophobic/hydrophilic character is irreversible, except for MIL-53, which offers a hydrophobic-hydrophilic transition originating from a structural phase transition. Indeed the network is hydrophobic in the large pores form and becomes hydrophilic when water enters in the structure for the narrow pores form. ${ }^{[21][22]}$

In contrast, PBA have been much less investigated for gas adsorption ${ }^{[23]}$ despite an excellent hydrothermal stability and high adsorption capacities observed for the adsorption of water ${ }^{[24,25]}, \mathrm{CO}_{2}{ }^{[26-28]}$ or ammonia. ${ }^{[29]}$ In this frame, Kawamoto et al highlighted the potential of PBAs for gas storage using different strategies, but to the best of our knowledge, their surface properties, in terms of hydrophobicity and hydrophilic character have never really been clarified up to now. ${ }^{[24]}$ Recently, we reported on a series of lipophilic PBA materials, highly efficient for the separation of different vapors, such as water and hydrocarbons. ${ }^{[25]}$ It was demonstrated that among this series of compounds, the $\mathrm{Co}\left[\mathrm{Co}^{\prime \prime \prime}(\mathrm{CN})_{6}\right]_{0.66}$ PBA exhibits an important hydrothermal stability and a high adsorption capacity allowing it to be greatly efficient for the hydrocarbons separation in both, dry or humid atmospheres. In the present communication, we demonstrate for the first time the ability of this lipophilic $\mathrm{Co}\left[\mathrm{Co}^{\prime \prime \prime}(\mathrm{CN})_{6}\right]_{0.66}$ PBA to reversibly switch its hydrophobic-hydrophilic character by coordination of water molecules on the CUS and optimize then its affinity for adsorption of molecules with different character, such as ethanol and $n$-hexane in humid and dry atmospheres.

The PBA $\mathrm{Co}\left(\mathrm{H}_{2} \mathrm{O}\right)_{\times}\left[\mathrm{Co}^{\prime \prime \prime}(\mathrm{CN})_{6}\right]_{0.66} \cdot \mathrm{yH}_{2} \mathrm{O}(\mathrm{x}+\mathrm{y}=5.2$ as determined by thermogravimetric analysis (Figure S1, Electronic Supporting Information (ESI)) $\mathbf{1}$ was obtained using the usual self-assembly reactions (see ESI). Figure 1 shows the fcc crystallographic structure of 1 , where the $\mathrm{Co}^{2+}$ and $\mathrm{Co}^{3+}$ ions are connected through the cyano-bridge forming a $3 \mathrm{D}$ cubic structure with pores of ca. $0.5 \mathrm{~nm}$. The electroneutrality in the structure is ensured by $\left[\mathrm{Co}^{\prime \prime \prime}(\mathrm{CN})_{6}\right]^{3-}$ vacancies, which generate randomly 
organized larger micropores of irregular shape (Figure S2, ESI).[30] This non-stoichiometry results in the presence of both, coordinated to the $\mathrm{Co}^{2+}$ ions (located close to a cyanometallate vacancy) and interstitial water molecules in the crystal structure. The TGA analysis shows a single step water loss indicating that it is not possible to quantitatively discriminate coordinated and interstitial water molecules. For this reason, the number of coordinated water molecules has been determined from the adsorption isotherms (vide infra), which leads to the formula $\mathrm{Co}\left(\mathrm{H}_{2} \mathrm{O}\right)_{2.45}\left[\mathrm{Co}{ }^{\prime \prime \prime}(\mathrm{CN})_{6}\right]_{0.66} \cdot 2.75 \mathrm{H}_{2} \mathrm{O}$ 1. Note that this is in agreement with solid-state NMR studies on other PBAs, which show that $x$ is in the range 1-3. ${ }^{[31]}$

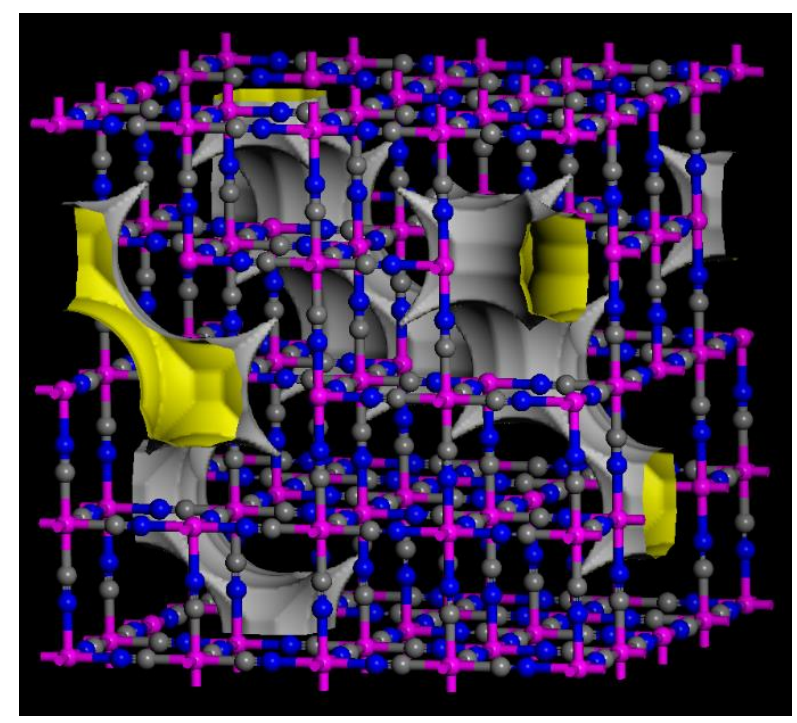

Figure 1. Co[Co $\left.\mathrm{Co}^{\prime \prime \prime}(\mathrm{CN})_{6}\right]_{0.66}$ structure showing the presence of nano and mesopores: atoms are represented with $\mathrm{N}$ (blue), C (grey), Co (pink). The structure has been built using structure issued from literature in which some $\left[\mathrm{Co}(\mathrm{CN})_{6}\right]^{3-}$ are missing. Only micropores are represented in the structure (due to the size of the unit cell considered for calculations) and the yellow and grey colours represent the free volume and the solvent accessible volume, respectively.

The textural analysis of the investigated PBA from nitrogen adsorption measurements at 77K (Figure S3, ESI) shows that the microporosity is confirmed by the high nitrogen uptake at low relative pressure of the adsorption isotherm, whereas the existence of mesopores is proved by the occurrence of a type I hysteresis loop at high relative pressure. Such mesopores (not considered in molecular simulations) can be formed by aggregation of zones with missing cyanometallates or by the interparticular voids. Nevertheless, the nitrogen adsorption does not give information about the surface chemistry of the solid as this probe is known to exert very limited interaction with any surface. As a consequence, there is no specific adsorption of nitrogen onto the CUS of the divalent metal centers of the PBA, implying the absence of particular feature that can be distinguished on the adsorption isotherms. For this purpose, water molecule appears as a species of choice for probing the hydrophilicity/hydrophobicity character of surfaces due to its ability to generate specific interactions with the host network. These interactions originate from the presence of the donor oxygen atom able to coordinate metal ions and also the possibility to form hydrogen bonding between water molecules.

Activation of 1 at $250^{\circ} \mathrm{C}$ during $8 \mathrm{~h}$ under a secondary vacuum generates the fully dehydrated sample Co[Co $\left.{ }^{\prime \prime \prime}(\mathrm{CN})_{6}\right]_{0.66} 2$ (Scheme 1). The corresponding water adsorption-desorption isotherms for this compound are shown in Figure 2. Note that all vapour sorption isotherms have been reproduced three times, which led to similar results. The equilibrium conditions are detailed in the ESI. The adsorbed amount at saturation is very high $\left(\sim 50 \mathrm{mg} \cdot \mathrm{g}^{-1}\right)$, which is close to what has already been reported for few PBA systems. ${ }^{25,32]}$ Interestingly, the adsorption curve exhibits a sigmoid-like shape with a small return back at low pressures, which is indicative of a metastable or delayed water adsorption process (black curve in Inset of Figure 2). Given that the relative pressure scale is related to a chemical potential one, this observation strongly suggests that the vapor phase requires a threshold chemical potential to be adsorbed in $\mathbf{2}$. Indeed, in the early stages of the adsorption process, the vapour phase is in a metastable state and has more energy than the thermodynamic equilibrium would require.

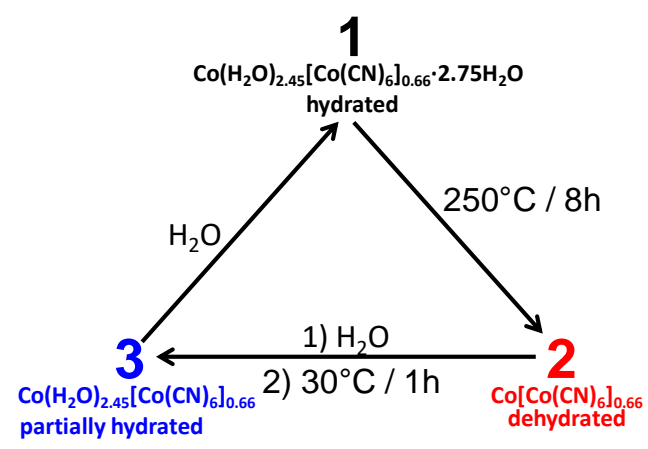

Scheme 1. Schematic representation of the synthesis of fully hydrated compound1, its fully dehydrated $\mathbf{2}$ and partially dehydrated $\mathbf{3}$ forms. 
However, water molecules do not have enough energy to enter the PBA framework due to low interaction existing with the framework. When adsorption occurs beyond the pressure threshold, the extent of adsorption is so large that the equilibrium pressure can be found at lower values and therefore decreases. An analogy can be made with surfusion processes in which a liquid in a metastable phase below its standard solidification temperature will suddenly transform to a solid phase, thus reaching a thermodynamical equilibrium at higher temperature. This phenomenon is due to the coordination of water molecules on $\mathrm{Co}^{2+}$ sites (CUS) at the first stage (chemisorption), which makes the initially hydrophobic character of the material hydrophilic. Indeed, at low vapor pressure, the network is hydrophobic that strongly limits water adsorption. Yet, above $p / p^{\circ}=0.03$, which corresponds to the chemical potential threshold, the character of PBA becomes hydrophilic, which in turn induces the adsorption of a large amount of water molecules.

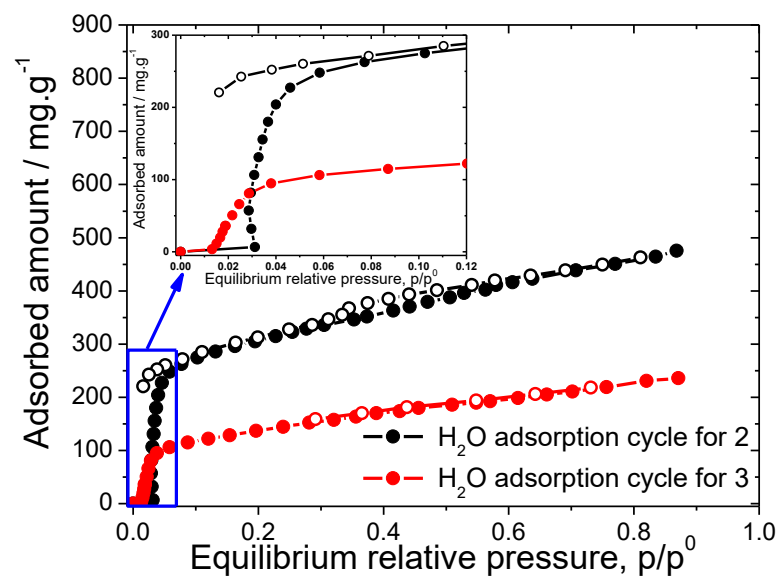

Figure 2. Experimental water adsorption-desorption isotherms for the first (black) and second (red) cycles obtained at $30^{\circ} \mathrm{C}$ for $\mathbf{2}$ and $\mathbf{3}$, respectively. The filled and empty symbols correspond to the adsorption and desorption isotherms, respectively. Inset: Magnification at low relative pressure.

The desorption branch of the sorption isotherm cycle (Figure 2) shows a large irreversibility at low relative pressure $\left(\sim 150 \mathrm{mg}^{-1} \mathrm{~g}^{-1}\right.$ extrapolated at zero pressure). Whereas water sorption is a process needing some activation energy, a large amount of water coordinated on the CUS remains captured by the host structure leading to the formula $\mathrm{Co}\left(\mathrm{H}_{2} \mathrm{O}\right)_{2.45}\left[\mathrm{Co} \text { "II }(\mathrm{CN})_{6}\right]_{0.66}$ for 3, which maintains the hydrophilic character of this material. The discrepancy between the irreversibly adsorbed water and the amount of water required to saturate the CUS according to the theoretical formula (around $200 \mathrm{mg} \cdot \mathrm{g}^{-1}$ ) shows that only $75 \%$ of the CUS (that is $150 \mathrm{mg} \cdot \mathrm{g}^{-1} / 200 \mathrm{mg}^{-1} \mathrm{~g}^{-1}$ ) are in strong interaction with water, in the desorption conditions applied here. Considering this result, the formula of 1 could be assumed as $\mathrm{Co}\left(\mathrm{H}_{2} \mathrm{O}\right)_{2.45}\left[\mathrm{Co}{ }^{\prime \prime \prime}(\mathrm{CN})_{6}\right]_{0.66} \cdot 2.75 \mathrm{H}_{2} \mathrm{O}$

It can be emphasized that the existence of sigmoid shaped adsorption isotherms has already been observed for $\mathrm{N}_{2}$ or $\mathrm{Ar}$ adsorption in some coordination polymers, ${ }^{[33]}$ as well as for water adsorption in $\mathrm{Zn}(\mathrm{II})$ - based PBAs or MIL-53(Fe) materials. ${ }^{[24][34]}$ This feature was explained by structural phase transitions occurring between empty and filled networks. In our case, the thermodiffraction measurements performed on 1 (Figure S4, ESI) with heating from room temperature to $200^{\circ} \mathrm{C}$ show only a unit cell contraction and a peak broadening upon heating. This fact rules out the hypothesis of a structural phase transition occurring during the activation/sorption process.

In order to confirm that this phenomenon comes from the chemisorption of water on the $\mathrm{Co}^{2+}$ centres (CUS), a second adsorptiondesorption isotherm was performed on the sample 3, which has a hydrophilic character, obtained after the first desorption and containing coordinated water molecules (see Scheme 1, ESI). As expected, the corresponding sorption isotherm (Figure 2 (red curves)) shows a very different shape in comparison to what was observed for the first water sorption cycle (for 2). The main differences are: (i) the absence of "a return back at low pressure", (ii) a much higher affinity for water as the water uptake occurs at half lower pressure; (iii) the saturation which is reached at lower adsorbed amounts; (iv) the reversibility of the second sorption cycle. This behaviour can be easily explained by the fact that in $\mathbf{3}$, a majority of CUS are already occupied by water molecules adsorbed after the first sorption cycle, which has turned the character of the material much more hydrophilic, as anticipated by Balmaseda et al. ${ }^{[30]}$

For a deeper understanding of this phenomenon, molecular simulations have been performed to provide a microscopic sight of the mechanism. Indeed it is well known that molecular simulation is able to discriminate the hydrophobic/hydrophilic character of the solid by determining: (I) the adsorption enthalpy (values lower than liquefaction enthalpy for water of around $-41 \mathrm{~kJ}$.mol ${ }^{-1}$ are representative of hydrophobic interactions), (ii) the shape of the adsorption isotherm (similarly to experimental results), and (iii) the comparison of interactions between framework and water molecules and interactions between water molecules to discriminate if water prefers to interact with the solid (hydrophilic character of the solid) or with other water molecules (hydrophobic character). The adsorption isotherms were modelled by Monte Carlo simulation first using completely dehydrated structures 2 and second, using the partially hydrated networks with 25,50, 75 and $100 \%$ of water molecules fixed on the CUS by chemisorption. The water adsorption isotherm for 2 shows that only a negligible amount of water may be adsorbed at saturation $\left(<1.5 \mathrm{mg} \cdot \mathrm{g}^{-1}\right)$ (Figure 3, $0 \%$ of water loading) and very low value of the estimated adsorption enthalpy of $-16 \mathrm{~kJ} \mathrm{~mol}^{-1}$ was obtained. This result unambiguously confirms the hydrophobic character of the fully dehydrated compound 2 , which is in very good agreement with the experimental data. Regarding structures with partial water loading at 25 and $50 \%$, the isotherms exhibit a sigmoid shape indicating that the hydrophobic character of the material is retained. However, at saturation the physisorbed amount of water increases to 18 and $35 \mathrm{mg}^{-1}$ for 25 and $50 \%$, respectively. The calculated adsorption enthalpy at low loading increases slightly but remains lower than $-41 \mathrm{~kJ}^{\mathrm{mol}}{ }^{-1}$ (Figure 3 ). In contrast, in the case of the structure with $75 \%$ of chemisorbed water, the shape of the obtained isotherm is now indicative of a 
hydrophilic character, since the slope of the curve is much higher from very low relative pressure. Furthermore, the calculated adsorption enthalpy is close to $-65 \mathrm{~kJ}^{\mathrm{mol}}{ }^{-1}$, which corresponds to a rather high interaction between water and the host structure.

For $100 \%$ occupation of CUS by water, the adsorption isotherm presents a classical Langmuirian shape, where the amount of the adsorbed water rapidly increases with pressure before a saturation plateau is reached. The values of the amount of adsorbed water at saturation and the calculated enthalpy are equal to $60 \mathrm{mg} \cdot \mathrm{g}^{-1}$ and $-70 \mathrm{~kJ} \cdot \mathrm{mol}^{-1}$, respectively. Note that the observed discrepancy with the experimental adsorbed amount may be explained by the fact that only physisorbed water molecules have been considered by the theoretical adsorption isotherms, whereas the adsorption of chemisorbed water loadings cannot be simulated by Monte-Carlo method using classical force fields. Indeed, it is impossible to simulate the formation of new covalent bonds of CUS-water molecules as a function of the water pressure by considering UFF and TIP4P-2005, but reactive force fields are required. In addition, mesopores have not been considered in the calculations.

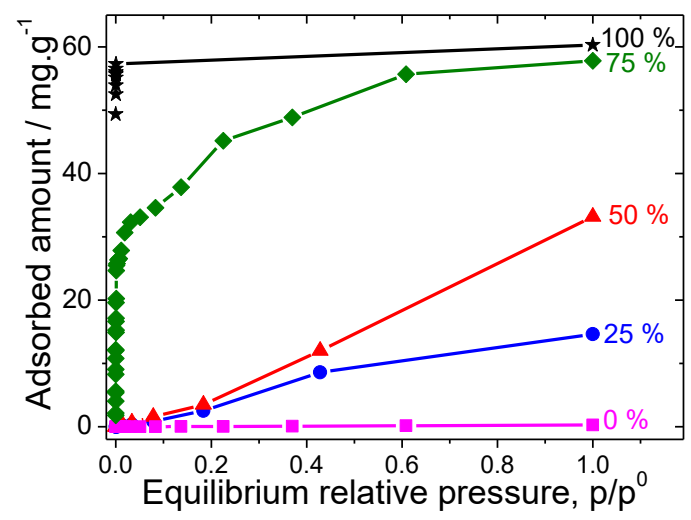

Figure 3. Water adsorption isotherms obtained by molecular simulations for $\mathrm{Co}_{0}\left[\mathrm{Co}^{\prime \prime \prime}(\mathrm{CN})_{6}\right]_{0.66} \mathbf{2}$ for $0 \%$ (pink squares), $25 \%$ (blue circles) $50 \%$ (red triangles), $75 \%$ (green diamonds) and $100 \%$ (black stars) of water molecules fixed (chemisorbed) on $\mathrm{Co}^{2+}$ sites (CUS).

Regarding the microscopic mechanisms occurring in the PBA pores as a function of the saturation of the CUS centers, it is possible to discriminate the hydrophobic-hydrophilic interactions existing in the pores for the physisorbed water. As chemisorption fails to be simulated using classical force fields, the strategy has consisted in imposing a ratio of chemisorbed molecules on the CUS as initial structures for Monte Carlo and to calculate the amount of physisorbed water present in the pores. With $100 \%$ of chemisorbed $\mathrm{H}_{2} \mathrm{O}$, the first water molecule adsorbed in the pores interacts with the chemisorbed molecules on the CUS by hydrogen bonds (see Figure S5) and the interaction distance is around $1.7 \AA$ (classical distance for $\mathrm{O} \cdots \mathrm{H}$ in $\mathrm{H}$-bond). This result further confirms the hydrophilicity of the solid containing $\mathrm{Co}^{2+}$ ions with coordinated water. In the case of larger loadings, chains can be described by combining water molecules with chemisorbed water and linear cluster can extend on a large distance (Figure S6, ESI). Furthermore, such organization allows the delocalisation of the $\mathrm{H}_{2} \mathrm{O}$ cluster to pass from one cavity to another one.

An experimental demonstration of the practical application of such materials with the lipophilic character presenting a hydrophobic/hydrophilic switch consists in the evaluation of the capacity for adsorption of guest molecules having different affinities, such as for instance ethanol and $n$-hexane. Firstly, we focus on anhydrous ethanol, which is able to provide hydrogen bonding with both, the host PBA framework and other ethanol molecules, as well as being involved in van der Waals interactions. Hence, the ethanol sorption isotherms were measured on samples 2 (fully dehydrated) and $\mathbf{3}$ (coordination of water on the CUS). They are reported in Figure 4 and in Figure S7 for the full sorption isotherms.

Similarly to water, the first ethanol sorption cycle performed on hydrophobic $\mathbf{2}$ is characterized by a sigmoid adsorption curve. It can be deduced that ethanol can be hardly adsorbed at low relative pressure, whereas a significant sorption occurs from a relative pressure threshold of around 0.025 .

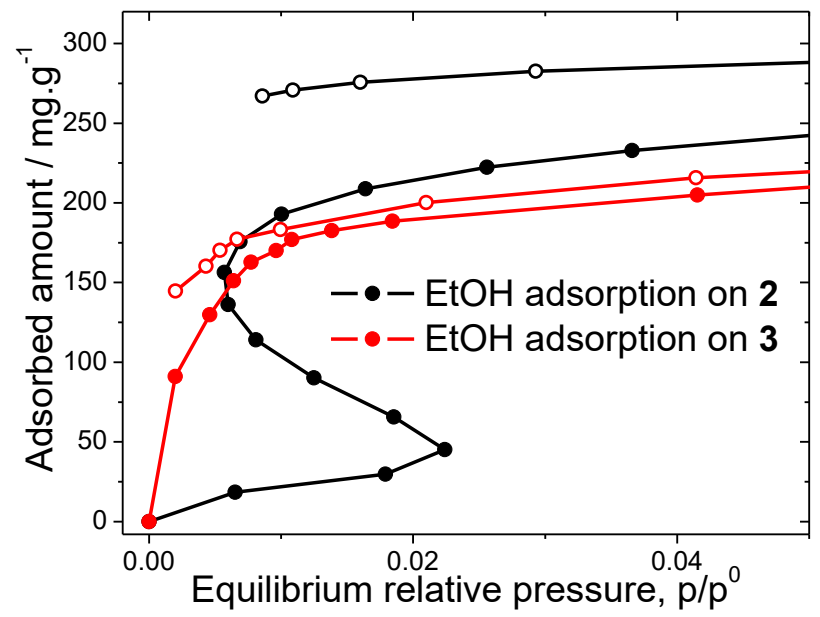


Figure 4. Ethanol sorption cycles performed at $30^{\circ} \mathrm{C}$ on $\mathbf{2}$ (black curves) and $\mathbf{3}$ (red curves). Adsorption and desorption branches represented by filled and empty symbols, respectively.

Once this threshold is overcome, ethanol is adsorbed in large quantities, up to $\sim 200 \mathrm{mg} \cdot \mathrm{g}^{-1}$ at the saturation plateau. The desorption branch shows a large irreversibility indicating that ethanol can also be chemisorbed, likely on the CUS of this material. The adsorbed amount in the "return back pressure" domain is higher than in the case of water adsorption (50 mg. $\mathrm{g}^{-1}$ and 10 mg. $\mathrm{g}^{-1}$, respectively for ethanol and water adsorption at $p / p^{\circ}=0.025$ ). This can be attributed to the additional van der Waals interaction between the host network and ethanol species. Furthermore, in the "return back pressure" domain, the equilibrium relative pressure decreases in a very pronounced fashion as the adsorbed amount increases, compared to water. This is consistent with the fact that ethanol interacts more easily with the PBA than water does.

In contrast, the second ethanol sorption cycle performed on the PBA 3 is characterized by a high affinity, with a high ethanol uptake since very low relative pressures. Additionally, this second sorption cycle is almost reversible. Since most of the CUS are engaged with water molecules, ethanol molecules only generate rather weak interaction with the PBA framework through van der Waals interactions. However, they could interact with chemisorbed water molecules (if present) by $\mathrm{H}$ bonds. These results clearly demonstrate that the adsorption capacity of materials may be optimised through hydrophobic/hydrophilic tuning depending on the affinity of the guest molecule.

The lipophilic character of the PBA was then investigated upon tuning the hydrophobic/hydrophilic balance of the material with the adsorption of a non polar $n$-hexane. As for ethanol, the sorption isotherms of $n$-hexane were performed on samples 2 and $\mathbf{3}$ (Figure 5 and Figure $\mathrm{S} 8$ for the full sorption isotherms).

A very high uptake of $n$-hexane can be noticed at very low relative pressure for fully dehydrated sample 2 , which is indicative of a high affinity between $n$-hexane and the hydrophobic PBA (black curves on Figure 5).

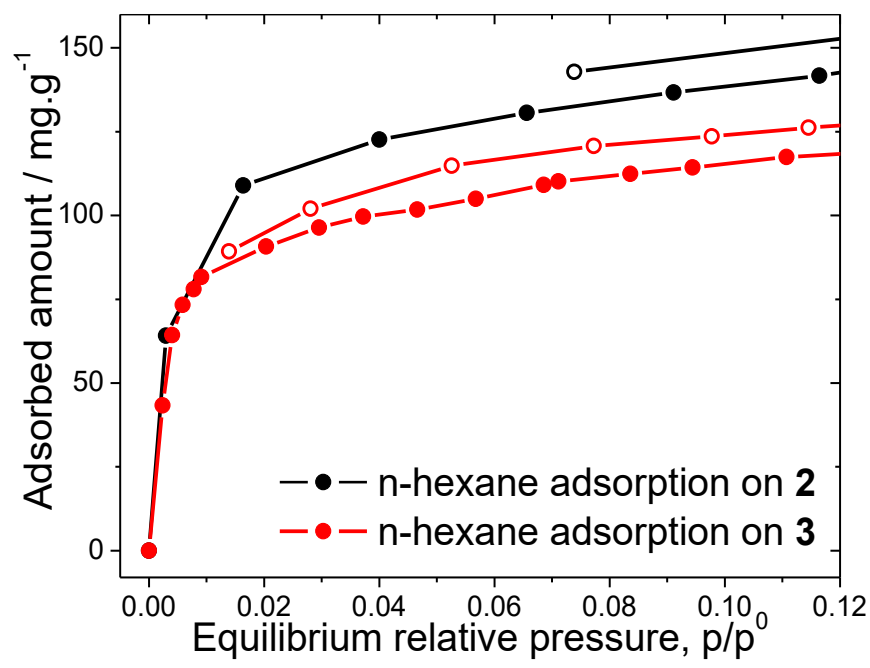

Figure 5. $n$-Hexane sorption cycles performed at $30^{\circ} \mathrm{C}$ on 2 and 3 . Adsorption and desorption branches represented by filled and empty symbols, respectively.

This is consistent with previously reported studies. ${ }^{[25]}$ Note that the activation treatment under a secondary vacuum $\left(10^{-4}\right.$ torr) for 1 hour at $30^{\circ} \mathrm{C}$ removed all $n$-hexane molecules adsorbed on the material, resulting in a full regeneration of 2 . Surprisingly, the adsorption-desorption isotherm performed with the sample $\mathbf{3}$ (presenting $\sim 75 \%$ of CUS chemisorbed with water molecules) is very similar. Particularly, the adsorbed amounts at saturation are comparable for both samples, which indicates that $n$-hexane species can still be adsorbed on the remaining sites even though $75 \%$ of the CUS are saturated with water. This can occur through a cooperative mechanism in which the very first adsorbed $n$-hexane molecules interact with other $n$-hexane molecules leading to their adsorption. Furthermore, the adsorption on these sites is completely reversible. Consequently, up to $\sim 75 \%$ water saturated CUS, the hydrophobic - hydrophilic character of the PBA does not affect the lipophilicity and therefore the $n$-hexane adsorption. These results demonstrate that gaseous hydrocarbons can efficiently be adsorbed from dry or humid streams.

This phenomenon is of clear interest for different technological applications, such as heterogeneous catalysis, sensing or vapour stream separation where humid hydrocarbons streams must be dried. To further illustrate this, Figure 6 shows the theoretical coadsorption of an equimolar mixture of water and $n$-hexane in the frame of the VOCs separation. Starting from the completely dehydrated solid 2, Monte Carlo simulations performed in the dry structure shows that the PBA has a clear preference for hydrocarbon molecules, whereas water molecules mostly form water clusters. Figure 6 highlights the co-existence of large red zones containing $n$-hexane molecules and smaller green ones where few water molecules form clusters, as already observed in the case of hydrophobic solids. In this particular case, water-water interactions are stronger than water-framework ones. On the contrary, starting from the same mixture $\mathrm{H}_{2} \mathrm{O}$-hexane, the simulated structure containing $100 \%$ of chemisorbed water is completely saturated by water molecules. However, this PBA does not adsorb any $n$-hexane molecules upon adsorption (Figure S9). Keep in mind that classical simulations fail to reproduce the chemisorption of water molecules when they are able to enter in the pores. Furthermore, the mesopores are not considered in the calculations. 


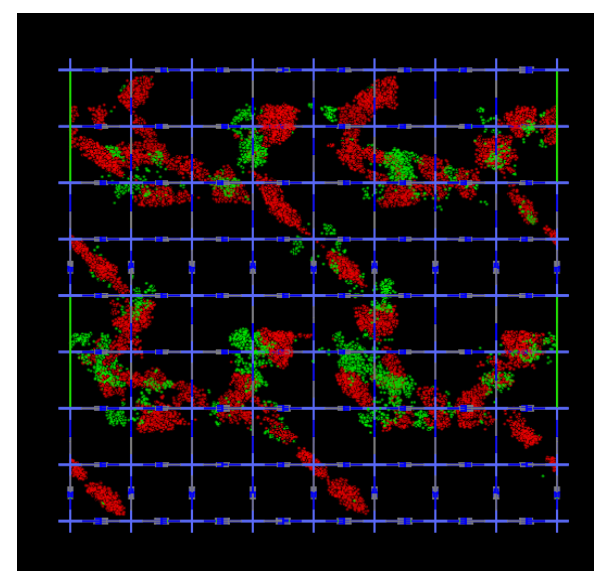

Figure 6. Modeled structure with the co-adsorption of water and $n$-hexane vapors for completely dehydrated $\mathrm{Co}_{0}\left[\mathrm{Co}^{\prime \prime \prime}(\mathrm{CN})_{6}\right]_{0.66} \mathbf{2}$. Red $z$ zones represent $n$-hexane molecules and green zones show water clusters.

In summary, we have demonstrated here for the first time that the hydrophilic/hydrophobic character of the PBA material can be tuned by a simple control of the coordinated water to the metal centres. While the completely dehydrated material shows a hydrophobic feature, a switch to a hydrophilic character is actuated by overcoming the water relative pressure threshold at $p / p^{\circ} \sim$ 0.03. The advantage of this unusual phenomenon has been demonstrated by optimized sorption of polar ethanol, able to engage hydrogen bonding and van der Waals interactions. Remarkably, the hydrophobic - hydrophilic character of the PBA does not alter its lipophilic balance and the material maintains its capacity to efficiently adsorb non polar species like $n$-hexane in humid or in dry atmosphere. This behaviour will permit to optimize the affinity of the host materials as a function of the nature of adsorbed molecules, which is of great interest for different applications.

Keywords: Prussian Blue Analogous • Hydrophilicity • Adsorption • Vapour • Chemically Unsaturated Sites

[1] G. Férey, J. Chem. Soc. Dalt. Trans. 2009, 4400-4415.

[2] D. Peralta, G. Chaplais, A. Simon-Masseron, K. Barthelet, C. Chizallet, A.-A. Quoineaud, G. D. Pirngruber, J. Am. Chem. Soc. 2012 , 134, 8115-8126.

[3] S. Kitagawa, R. Kitaura, S. Noro, Angew. Chem. Int. Ed. Engl. 2004, 43, 2334-2375.

[4] K. W. Chapman, P. D. Southon, C. L. Weeks, C. J. Kepert, Chem. Commun. 2005, 0, 3322-3324.

[5] J. Duan, W. Jin, R. Krishna, Inorg. Chem. 2015, 54, 4279-4284.

[6] G. Férey, Chem. Soc. Rev. 2008, 37, 191-214.

[7] S. S. Kaye, J. R. Long, J. Am. Chem. Soc. 2005, 127 (18), 6506-6507.

[8] P. Przychodzeń, T. Korzeniak, R. Podgajny, B. Sieklucka, Coord. Chem. Rev. 2006, 250, 2234-2260.

[9] A. Noureddine, P. Trens, G. Toquer, X. Cattoen, M. Wong Chi Man, Langmuir 2014, 30, 12297-12305

[10] U. D. Thach, P. Trens, B. Prelot, J. Zajac, P. Hesemann, J. Phys. Chem. C 2016, 120, 27412-27421.

[11] J. Lee, O. K. Farha, J. Roberts, K. A. Scheidt, S. T. Nguyen, J. T. Hupp, Chem. Soc. Rev. 2009, 38, $1450-9$.

[12] C. R. Wade, T. Corrales-Sanchez, T. C. Narayan, M. Dincă, Energy Environ. Sci. 2013, 6, 2172.

[13] C. A. Fernandez, S. K. Nune, H. V. Annapureddy, L. X. Dang, B. P. McGrail, F. Zheng, E. Polikarpov, D. L. King, C. Freeman, K. P. Brooks, Dalt. Trans. 2015, 44, 13490-13497.

[14] T. Wittmann, R. Siegel, N. Reimer, W. Milius, N. Stock, J. Senker, Chem. - A Eur. J. 2015, 21, 314-323.

[15] G. E. Cmarik, M. Kim, S. M. Cohen, K. S. Walton, Langmuir 2012, 28, 15606-15613.

[16] T. A. Makal, X. Wang, H. C. Zhou, Cryst. Growth Des. 2013, 13, 4760-4768.

[17] C. Yu, S. Bourrelly, C. Martineau, F. Saidi, E. Bloch, H. Lavrard, F. Taulelle, P. Horcajada, C. Serre, P. L. Llewellyn, et al., Dalt. Trans. 2015, 44, 19687-19692.

[18] K. Tan, N. Nijem, Y. Gao, S. Zuluaga, J. Li, T. Thonhauser, Y. J. Chabal, CrystEngComm 2015, 17, 247-260.

[19] A. B. Spore, N. L. Rosi, CrystEngComm 2017, 19, 5417-5421.

[20] A. Nalaparaju, X. S. Zhao, J. W. Jiang, J. Phys. Chem. C 2010, 114, 11542-11550.

[21] F. Salles, S. Bourrelly, H. Jobic, T. Devic, V. Guillerm, P. L. Llewellyn, C. Serre, G. Ferey, G. Maurin, J. Phys. Chem. C 2011, 115, 10764-10776.

[22] F. X. Coudert, A. U. Ortiz, V. Haigis, D. Bousquet, A. H. Fuchs, A. Ballandras, G. Weber, I. Bezverkhyy, N. Geoffroy, J. P. Bellat, et al., J. Phys. Chem. C 2014, 118, 5397-5405.

[23] M. Asai, A. Takahashi, Y. Jiang, M. Ishizaki, M. Kurihara, T. Kawamoto, J. Phys. Chem. C 2018, 122, 11918-11925.

[24] J. Roque, E. Reguera, J. Balmaseda, J. Rodriguez-Hernandez, L. Reguera, L. F. del Castillo, Microporous Mesoporous Mater. $2007,103,57-71$.

[25] L. Boudjema, E. Mamontova, J. Long, J. Larionova, Y. Guari, P. Trens, Inorg. Chem. 2017, 56, 7598-7601.

[26] J. Canivet, A. Fateeva, Y. Guo, B. Coasne, D. Farrusseng, Chem. Soc. Rev. 2014, 5594-5617.

[27] A. Zarate, R. A. Peralta, P. A. Bayliss, R. Howie, M. Sanchez-Serratos, P. Carmona-Monroy, D. Solis-Ibarra, E. Gonzalez-Zamora, I. A. Ibarra, RSC Adv. 2016, 6, 9978-9983.

[28] A. U. Ortiz, A. P. Freitas, A. Boutin, A. H. Fuchs, F.-X. Coudert, Phys. Chem. Chem. Phys. 2014, 16, 9940-9949. 
[29] A. Takahashi, H. Tanaka, D. Parajuli, T. Nakamura, K. Minami, Y. Sugiyama, Y. Hakuta, S.-I. S. Ohkoshi, T. Kawamoto, J. Am. Chem. Soc. 2016, 138, 6376-6379.

[30] J. Balmaseda, E. Reguera, J. Rodríguez-Hernández, L. Reguera, M. Autie, Microporous Mesoporous Mater. 2006, 96, $222-236$.

[31] A. Flambard, F. H. Köhler, R. Lescouëzec, Angew. Chem. Int. Ed. Engl. 2009, 47, 1673-1676.

[32] P. Küsgens, M. Rose, I. Senkovska, H. Fröde, A. Henschel, S. Siegle, S. Kaskel, Microporous Mesoporous Mater. 2009, 120, 325-330.

[33] D. Tanaka, K. Nakagawa, M. Higuchi, S. Horike, Y. Kubota, T. C. Kobayashi, M. Takata, S. Kitagawa, Angew. Chemie, Int. Ed. $2008,47,3914-3918$.

[34] N. A. Ramsahye, T. K. Trung, S. Bourrelly, Q. Yang, T. Devic, G. Maurin, P. Horcajada, P. L. Llewellyn, P. Yot, C. Serre, et al., J. Phys. Chem. C 2011 $115,18683-18695$. 
